\title{
A IMPORTÂNCIA DA INTEGRAÇÃO MÉXICO-MERCOSUL PARA A NEGOCIAÇÃO DA ALCA *
}

\author{
Ana Paula Martinez \\ Aluna do Curso de Graduação da Faculdade de \\ Direito da Universidade de São Paulo
}

\begin{abstract}
Resumo:
O processo de criação da Área de Livre Comércio das Américas entrou em sua fase final de negociação. Os Estados Unidos tentam impor o modelo no qual o país seria o eixo dos acordos bilaterais, o que poderia acabar por levá-lo a ser o único juiz do processo de integração do continente americano. Cabe às duas potências regionais da América Latina, Brasil, representando o Mercosul, e México, unirem-se com o intuito de barrar a tentativa dos EUA de conduzir o processo de forma unilateral, contribuindo para o equilíbrio das relações nas Américas. Porém, para obter sucesso nessa empreitada, faz-se necessário uma integração México-Mercosul não num modelo " $5+1$ " devido à peculiaridade das relações que o México tem com os Estados Unidos, mas numa relação que poderia ser expressa da seguinte forma: “ $(4+1)+1$ ".
\end{abstract}

\begin{abstract}
:
The process of creation of the Free Trade Area of the Americas has entered its final phase of negotiations. The United States of America have tried to impose a model wherein it would coordinate all bilateral agreements, a situation which would cause the USA to be the only judge in the integration process of the Americas. The two greatest economies of Latin America, namely Brazil, representing with the Mercosur, and Mexico, shall join forces with the aim to barr the attempt of the United States to lead the process individually, thus contributing towards a greater balance in the relations within the Americas. However, in order to succeed in this attempt, it is necessary to achieve an integration between Mexico and Mercosur, not in a " $5+1$ " model, due to the peculiar relations that Mexico has with the USA, but in a relationship that could be expressed in the following manner: “ $(4+1)+1$ ".
\end{abstract}

Unitermos: ALCA; ALCA e Mercosul; integração regional.

\section{Introdução}

"Dans la vie, il n'y a pas de solutions, il y a des forces en marche: il faut les créer et les solutions suivent." Saint Exupéry - Vol de Nuit

\footnotetext{
- Monografia vencedora do II Conçurso de Monografias Franco Montoro, realizado pela Associação de Antigos Alunos da Faculdade de Direito da Universidade de São Paulo, pelo Centro Acadêmico XI de Agosto e pela Câmara de Indústria, Comércio e Turismo Brasil-México no ano de 2003.
} 
A complexidade crescente das questões relacionadas ao comércio internacional fez com que o tema da integração continental adquirisse importância estratégica para os países da América Latina.

Em 1990, o então presidente dos EUA, George H. Bush, lançou a Iniciativa para as Américas (Enterprise for the Americas Iniciative - EAI), objetivando o aprofundamento das relações daquele país com a América Latina. Esse projeto foi retomado por seu sucessor, Bill Clinton, e na $1^{2}$ Cúpula das Américas, realizada em 1994, chefes de Estados de 34 países americanos (todos os países do continente, à exceção de Cuba) decidiram concluir até 2005 a constituição da Área de Livre Comércio das Américas (ALCA - em inglês FTAA - Free Trade Area of the Americas). Essa área de livre comércio abrangeria um mercado de 740 milhões de pessoas, com um produto interno bruto (PIB) total de US\$ 10,8 trilhões. Desde então, o esforço para unir as economias do continente americano $\mathrm{cm}$ um único acordo de livre comércio tem progredido.

Porém, deve-se ter em conta que a abertura de mercados, apesar de necessária, não é condição suficiente para se prosperar em uma economia global competitiva. Antes de dar o passo definitivo em direção à integração continental, devem ser estabelecidas condições que garantam vantagens competitivas para os países americanos e que permitam um equilíbrio entre ganhos e concessões para os 34 países. As negociações são complexas, uma vez que envolvem países com economias de porte muito díspares: de pequenas ilhas do Caribe a países-continente como Brasil, Canadá e Estados Unidos; de países que produzem um número limitado de produtos básicos à sofisticação de três das dez maiores potências econômicas do planeta.

A idéia de integração continental americana foi seguida por respostas entusiásticas de grande parte dos países do continente. Exceções notáveis a esse entusiasmo inicial foram as do México e do Brasil, as duas potências de grande porte da economia latino-americana. O México porque já estava incluído num acordo de livre comércio com os Estados Unidos e o Canadá, e o Brasil, porque queria antes fortalecer o Mercosul como bloco regional e mostrava-se reticente quanto às intenções americanas.

O presente trabalho procurará demonstrar a importância de fortalecer a integração entre México e Mercosul para a negociação da ALCA como forma de contrapor-se à dependência dos países latino-americanos com relação aos Estados Unidos, principalmente na atual fase final de negociação em que se encontra o processo, fundamental para o avanço da ALCA. Ressalte-se que ao ser feita referência ao Mercosul, será dada ênfase ao Brasil, visto ser este seu principal membro, responsável por chefiar as negociações do bloco com os Estados Unidos. 


\section{Breve Histórico da ALCA}

Em 1990, o ex-presidente dos EUA, George H. Bush, lançou a Iniciativa para as Américas, proposta de integração comercial de todos os países da América, com exceção de Cuba' Essa iniciativa demonstrava que a América voltava a figurar entre as prioridades da política externa dos Estados Unidos ${ }^{2}$, diante da ameaçadora ascensão do Japão e do processo de unificação da Europa.

Em dezembro de 1994 ocorreu a $1^{\text {a }}$ Cúpula das Américas, em Miami, nos Estados Unidos. Os trinta e quatro países americanos decidiram concluir até 2005 a criação da ALCA, cujo objetivo seria eliminar as barreiras ao comércio e aos investimentos nas Américas. As decisões da Cúpula estão expressas em uma Declaração de Princípios e em um Plano de Ação, cujo amplo conteúdo inclui questões como direitos humanos, pobreza e desenvolvimento sustentável. Em abril de 1998, ocorreu em Santiago, Chile, a $2^{\mathrm{a}}$ Cúpula das Américas, que marcou o início efetivo das negociações para a formação da ALCA. A $3^{\mathrm{a}}$ Cúpula das Américas foi celebrada em Québec, Canadá, em abril de 2001. Paralelamente a essas Cúpulas, são celebradas as Reuniões Ministeriais sobre Comércio (“Reunião Ministerial”), sendo que a $3^{a}$ Reunião Ministerial ocorreu em maio de 1997, em Belo Horizonte, Brasil ${ }^{3}$ Cabe dizer que a

I. Nas palavras de George H. Bush, a área de livre comércio iria "do Yukon à Patagônia". Os países que farão parte da ALCA, se as negociações forem concluídas com sucesso, são: Antígua e Barbuda, Argertina, Bahamas, Barbados, Belize, Bolívia, Brasil, Canadá, Chile, Colômbia, Costa Rica, Dominica, Equador, El Salvador, Estados Unidos da América, Granada, Guatemala, Guiana, Haiti, Honduras, Jamaica, México, Nicarágua, Panamá, Paraguai, Peru, República Dominicana, São Cristóvão e Névis, Santa Lucia, São Vicente e Las Granadinas, Suriname, Trinidad e Tobago, Uruguai e Venezuela.

2. J.A.G. ALBUQUERQUE, A ALCA na política externa brasileira in Política Externa, v. 10, n. 2 , São Paulo: Paz e Terra, p. 8, ressalta que não constituiu surpresa essa retomada de interesse norte-americano, até porque a iniciativa de integração continental apenas atestou o continuado interesse norte-americano nas Américas. Em suas palavras, "se o tema emergiu fortuitamente é porque estava muito próximo da superfície". Cabe lembrar que a idéia de integração hemisférica não é nova. O presidente norte-americano Grover Cleveland, em 1887, propôs às naçōes americanas "uma base mais sólida e prática" do que a "contida na Doutrina Monroe" mediante uma união aduaneira "com troca de produtos, livre de impostos", citado por M. BANDEIRA, Relações Brasil-Estados Unidos no contexto da globalizaçāo, 2" ed. revista e ampliada, São Paulo: Senac, 1998, p. 183.

3. J.A.G. ALBUQUERQUE, A ALCA na política externa brasileira in Política Externa, cit., p. 13, indica esse fato como determinante do engajamento do Brasil nas negociações: "Finalmente, uma razão que pode parecer banal constitui um clássico da diplomacia política: nenhum país anfitr: fracasso de um reunião em que ele é sede. Se existe um inconsciente dos Estados-nação, quando a diplomacia brasileira aceitou hospedar o Fórum e a Reunião Ministerial de Belo Horizonte e, depois, Santiago, quando admitiu co-presidir a fase final de negociação da ALCA, inconscientemente o destino estava selado." As demais Reuniōes Ministeriais celebraram-se em Denver, Estados Unidos (junho de 1995), Cartagena, Colômbia (março de 1996), San José, Costa Rica (março de 1998), Toronto, Canadá (novembro de 1999), Buenos Aires, Argentina (abril de 2001) e Quito, Equador (novembro de 2002). 
estrutura das negociações para a formação da ALCA tem um formato de rodízio para a presidência e coordenação de suas instâncias negociadoras ${ }^{4}$

\section{A Negociação conjunta do Mercosul}

A idéia dos Estados Unidos para a negociação da ALCA é ser o eixo dos acordos bilaterais (modelo hub and spoke), o que acabaria por elevar os Estados Unidos como únicos juízes do processo de integração do continente americano. Entretanto, desde a Iniciativa das Américas, o Brasil liderou a iniciativa de negociação em conjunto (Mercosul de uma parte e Estados Unidos da outra). Esse modelo peculiar de negociação com os Estados Unidos ficou conhecido como " $4+1$ " 5 e mostra-se vantajosa para todos os países do Mercosul: para o Brasil, serve como garantia contra um eventual isolamento em sua posição defensiva contra a ALCA, e para os demais países, garante maior peso no caso de uma eventual adesão.

Essa posição vem sendo reafirmada em encontros entre os presidentes dos países membros do Mercosul. Na primeira quinzena de maio de 2003, ${ }^{6}$ o presidente do Brasil, Luiz Inácio Lula da Silva, e o presidente uruguaio, Jorge Batlle Ibáñez, defenderam em Brasília, em um comunicado conjunto de 35 pontos, a unidade do Mercosul nas negociações internacionais, entre as quais as da ALCA. Em conjunto, os

4. AALCA estrutura-se da seguinte forma: (i) instâncias negociadoras: (a) Presidência das Negociações: obedece a um rodízio de 18/18 meses; (b) Comissão de Negocią̧ōes Comerciais: responsável pela supervisão das negociações; (c) Grupos de Negociações: são nove grupos (acesso a mercados, investimentos, serviços, compras governamentais, solução de controvérsias, agricultura, direitos de propriedade intelectual, subsídios e política de concorrência) cuja presidência muda a cada 18 meses; (ii) instâncias não negociadoras: são as seguintes: (a) Grupo Consultivo sobre economias menores; (b) Comitê conjunto de Especialistas do Governo e do Setor Privado sobre Comércio Eletrônico; e (c) Comitê de Representantes Governamentais sobre a participação da sociedade civil. Tanto os Grupos de Negociações como as instâncias não negociadoras reportam-se ao Comitê de Negociações Comerciais. Em caráter de assistência técnica ao processo de integração, há uma comissão tripartite,composta pelo Banco Inter-Americano (BID), Comissão das Nações Unidas para a América Latina e Caribe (CEPAL) e Organização dos Estados Americanos (OEA). Foi estabelecido ainda que as negociaçōes teriam lugar na Secretaria Administrativa Temporária, cuja sede seria estabelecida, em caráter rotativo, em três cidades - Miami, Estados Unidos (de $I^{\circ}$ de maio de 1998 a 28 de fevereiro de 2001), Cidade do Panamá, Panamá (de $1^{\circ}$ de março de 2001 a 28 de fevereiro de 2003) e Puebla, México (de $I^{\circ}$ de março de 2003 a 31 de dezembro de 2004).

5. J.A.G. ALBUQUERQUE, a ALCA na política externa brasileira in Politica Externa, cit., p. 11, ressaltou que essa forma de negociação foi tanto mais peculiar, visto que à época o Mercosul ainda não estava formalizado como entidade internacional. A personalidade jurídica internacional do bloco só foi reconhecida quando da assinatura do Protocolo de Ouro Preto sobre aspectos institucionais, em dezembro de 1994.

6. V. Guzeta Mercantil de 14 de maio de 2003, editorial, p. A-3. 
países membros do Mercosul adquirem maior poder de barganha, conseguindo maior peso, por exemplo, para alcançar as almejadas concessões substanciais na área agrícola. O ministro das Relações Exteriores do Brasil, Celso Amorim, ressalta a importância de que as mesmas propostas sejam apresentadas pelo Brasil, Argentina, Paraguai e Uruguai para evitar a concorrência desleal dentro do próprio bloco, o que poderia resultar, conseqüentemente, em seu desaparecimento ${ }^{7}$

$\mathrm{Na}$ primeira troca de ofertas para a formação da ALCA, em abril de 2003, os países do Mercosul entregaram propostas comuns para a liberalização comercial nas áreas de bens industriais e agrícolas. Em serviços, o bloco ficou dividido: Uruguai e Paraguai apresentaram suas listas, enquanto Brasil e Argentina adiaram a apresentação de propostas. Os quatro países membros do Mercosul postergaram as ofertas para investimentos e compras governamentais ${ }^{\sharp}$

Por sua dimensão e peso econômico, o Brasil assume naturalmente o papel de âncora e motor não só do bloco sub-regional Mercosul, mas também da economia sul-americana em seu conjunto9 ${ }^{9}$ Tendo isso em vista, abaixo será discutido o peso do Brasil nas negociações da ALCA.

\section{I O peso do Brasil nas negociações da ALCA}

O Brasil posiciona-se com cautela no que se refere à negociação da ALCA. Segundo pesquisa da Fiesp/Vox Populi ${ }^{10}$, para a maioria da população brasileira

7. M. CARMO, Mercosul decide negociar em conjunto entrada na ALCA in Valor Econômico, 5 de fevereiro de 2003, $I^{\circ}$ Caderno.

8. Segundo D. RITTNER, Itamaraty tem novo negociador para ALCA, Gazeta Mercantil de 16, $17 \mathrm{e}$ 18 de maio de 2003, p. A-5, Samuel Pinheiro Guimarães pode ser apontado como o principal articulador da estratégia brasileira de deixar de entregar propostas nas áreas de investimentos, compras governamentais e serviços.

9. Segundo dados fornecidos pelo Departamento de Comércio Exterior da Fiesp, citada por R. NOGUEIRA, "Lula quer ajuda do companheiro Bush para mudar o modelo", Primeira Leitura, n. I0, dezembro de 2002, p. 26, o Brasil responde por 6,38\% dos 9,03\%do PIB total da ALCA detido pelo Mercosul. Cabe dizer que o Nafta detém 82,23\% de participação do PIB total da ALCA. Excluindo-se o Nafta, a relação do PIB Brasil/ALCA sobe para 49,98\%, de um total de 70,71\% detido pelo Mercosul.

10. Pesquisa realizada em abril de 2002 e publicada na Revista Primeira Leitura n. 10, dezembro de 2002 , p. 32. Segundo essa pesquisa, $9 \%$ da população brasileira acredita que o país deve se associar o mais rapidamente à ALCA, 30\% acredita que o Brasil deva negociar favorecendo os setores mais competitivos da economia brasileira, $35 \%$ pensa que o país só deve negociar a ALCA se uma agenda interna de reformas estiver também sendo conduzida, 22\% acredita que a adesão do Brasil deve ser postergada para que mais setores da economia tenham tempo para se ajustar, $3 \%$ acredita que o Brasil não deveria aderir ao processo e $1 \%$ não respondeu ao questionário de pesquisa. 
(35\%), o Brasil só deve negociar a ALCA se uma agenda interna de reformas estiver também sendo conduzida. Alguns dos argumentos que justificam uma posição conservadora para uma integração continental americana gradual por parte do Brasil são os seguintes ${ }^{11}$ :

i) o Brasil tem um perfil de comércio bem equilibrado internacionalmente e possui interesses em todas as regiões do mundo, configurando-se como um global trader. IIsando a analogia de Vera THORSTENSEN ${ }^{12}$ a melhor imagem que se pode fazer de tal situação é a de um jogo em que o Brasil atua, certas vezes sozinho, certas vezes coordenado com o Mercosul, diante de vár: is tabuleiros diferentes de xadrez, confrontando um número diverso de parceiros e com peças e estratégias que se entrelaçam, dentro de um grande jogo internacional ${ }^{13}$;

ii) o Brasil deve focar sua atenção primeiro no Mercosul, uma vez que, como bem apontado por Celso Lafer, enquanto o Mercosul é um destino, a ALCA é apenas uma opção ${ }^{14}$ Essa superioridade do Mercosul exige conceder-lhe toda a prioridade e, além disso, abster-se de qualquer engajamento que possa a vir a torná-lo menos do que prioritário. Além disso, o Mercosul não embute desigualdades de dimensões da mesma ordem que a ALCA incluiria $^{15}$;

iii) as prioridades dos Estados Unidos estariam na Europa e na Ásia Pacífico, portanto a negociação de uma área livre comércio

11. Cf. J.A.G. ALBUQUERQUE, A ALCA na política externa brasileira ob. cit., p. 14.

12. V. THORSTENSEN, O Brasil diante de um tríplice desafio: negociações simultâneas da OMC, da ALCA e do acordo CE/Mercosul in Política Externa, vol. 10, n. 3, São Paulo: Paz e Terra, p. 93.

13. O que não afasta a grande importância das relações Brasil-Estados Unidos. Em 2002, os Estados Unidos tornaram-se o principal destino das exportações brasileiras. O país comprou $25,5 \%$ do total das exportações brasileiras.

14. Nesse sentido, ver R. T. da COSTA, ALCA 2005: destino ou opção, in Política Externa, v. 10, n. 2, São Paulo: Paz e Terra, pp. 102-111.

15. Nesse sentido, o presidente da Argentina, Néstor Kirchner já expressou claramente sua prioridade com o Mercosul e com as relaçôes com o Brasil. Nas palavras de Kirchner, "A ALCA será tratada em seu tempo e em sua oportunidade. As pendências do Mercosul têm de ser resolvidas antes." V. R. TRINDADE, Planal to e Itamaraty aprovam Kircher e Lavagna no poder in Gazeta Mercantil, 16, 17 e I8 de maio de 2003, p. A-4. 
continental seria uma mera ação diversionista visando, no mínimo, a limitar a integração no Cone Sul e, no máximo, a inviabilizá-la, de modo a manter o restante do continente sob sua dependência. Freqüentemente, esse argumento foi empregado por autores que, ao mesmo tempo, também criticavam a ALCA como fruto direto do unilateralismo dos Estados Unidos e sua busca incessante de marcar sua hegemonia na região;

iv) um acordo com a União Européia é mais vantajoso para o Brasil por razões diversas, desde o paralelismo entre os dois modelos de integração até o interesse análogo em limitar a hegemonia americana, passando pelo caráter menos unilateral das políticas comerciais européias; $\mathrm{e}$

v) na hipótese de um aumento da concorrência com os Estados Unidos e partindo do pressuposto da maior competitividade global da economia americana, a indústria e o setor de serviços nacionais poderiam ser sucateados. Há uma preocupação compartilhada entre o Governo e a iniciativa privada de que determinados produtos brasileiros não são competitivos o suficiente em um cenário de livre comércio com os Estados Unidos ${ }^{16}$

Por todas essas razões, o Brasil vem discutindo cada ponto da integração continental com cautela. O país compartilha com os Estados Unidos a Presidência do Comitê de Negociações Comerciais da ALCA desde o fim de 2002 e não seria oportuno o país ser acusado de falta de comprometimento com a idéia de livre comércio. Nesse sentido, o Brasil já abandonou a tática inicial de não-envolvimento em vista do risco de um avanço tal nas negociações entre os terceiros Estados que ao Brasil só restaria $f$

16. Segundo o Anuário de Competitividade Mundial 2003, estudo com base em pesquisa com empresários internacionais elaborado pela Escola de Administração de Lausanne (IMD) da Suíça, levando em consideração o desempenho das empresas em 2002, o Brasil aparece na $21^{2}$ posição entre 30 países com mais de 20 milhões de habitantes, o que representa perda de seis posiçōes com relação ao relatório anterior. Foi a pior posição alcançada pelo Brasil desde 1997. Isso ocorreu em função da precariedade da educação, da falta de tecnologia de ponta, da violência e de carga tributária e juros altos. O desempenho de outros países da América Latina contemplados pela pesquisa (Argentina, Chile, Colômbia, México e Venezuela) foi negativo também. Na classificação geral de 2003, todos os países, à exceção da Colômbia, apresentaram perda no ranking de competitividade geral, se comparada com a classificação de 2002. A Argentina, principal parceiro do Brasil no Mercosul, alcançou a $29^{2}$ posição, perdendo três posições se comparado com aquela alcançada em 2002, motivada pela queda do PIB (11,2\% eın 2002). Esse estudo vem servindo, desde 1986, como importante indicador das vantagens e desvantagens competitivas enfrentadas por 51 países. 
a opção de aceitar tudo da forma como tinha sido negociado ou ficar de fora. Passou, então, a adotar uma tática de participação conflituosa, adequada a de um país como o Brasil, com dimensão e estrutura de interesses irredutíveis às de um país periférico.

A co-presidência com os Estados Unidos na fase decisiva das negociações, além de indicar o peso político e econômico do Brasil no hemisfério, permite ao país influir mais diretamente no processo, facilitando uma defesa mais articulada dos interesses brasileiros, em conjunto com aqueles do Mercosul. Assim, procurar-se-á garantir resultados equilibrados e a efetiva observância dos princípios negociais consignados nas declarações ministeriais, em particular os princípios do consenso, do single undertaking, dos resultados equilibrados e vantajosos para 0 conjunto dos países e da coexistência da ALCA com os acordos comerciais sub-regionais mais profundos ${ }^{17}$

\section{Integração México-Brasil e México-Mercosul}

Muito se tem discutido sobre os efeitos da criação da ALCA em relação ao Brasil e ao México, consideradas potências médias recém-industrializadas ${ }^{18} \mathrm{e}$ líderes econômicos e políticos da América Latina.

Brasil e México apresentam peso econômico e demográfico suficientes ${ }^{19}$ para exercerem influência real nos negócios internacionais. Nas últimas seis décadas, Brasil e México compartilharam uma história econômica bastante similar. Entre 1940 e 1980, alcançaram algumas das mais elevadas taxas de crescimento do mundo, em média de $6 \%$ ao ano. Ademais, ambos os países tendem a desempenhar funções determinantes na conformação e na dinâmica dos sistemas e arranjos políticos regionais.

17. R. A. BARBOSA, O Impacto da ALCA sobre o Mercosul, in Revistu Brrasileira de Comércio Exterior RBCE, Rio de Janeiro: Fundação Centro de Estudos do Comércio Exterior, p. 6.

18. Segundo R. KEOHANE, Small States in the International Politics, v. 23, n. 2, 1969, p. 292, o estudo das potências médias recém-industrializadas surgiu por volta dos anos 60 , tanto em decorrência do Movimento dos Países Não-Alinhados como do surgimento de países industrializados entre os países em desenvolvimento. A definição de potências médias leva em conta dois aspectos fundamentais: (i) a capacidade internacional relativa desses países enquanto atores globais; $\mathrm{e}$ (ii) o papel de destaque em seus respectivos sistemas regionais. Sobre o assunto, ler também R. U. SENNES, ALCA e as Potências Médias: Brasil e México. Série ALCA. São Paulo: FTD, 1998, v. 3.

19. Segundo P. HAKIM, Brasil e México: duas maneiras de ser global in Política Externa, v. 10, n. 4, São Paulo: Paz e Terra, p. 95, em 2001, o Brasil era o quinto maior país do mundo em termos de população, possuindo a oitava maior economia em termos globais. O México era o décimo país mais populoso, ocupando o décimo segundo lugar na economia mundial. Ambos os países apresentam uma grande e diversificada demanda interna por produtos, constituindo-se em grandes mercados. 
Sua forte presença tende a lhes conferir grande influência política, econômica e cultural, assim como papéis de liderança e estruturação dos sistemas regionais que integram.

Porém, dispondo de uma presença internacional destacada em termos de território, população e importância econômica, as potências médias, como o Brasil e o México, não chegam a influenciar o sistema internacional atuando individualmente. Repetidamente, tanto o Brasil quanto o México têm agido no sentido de reforçar suas participações em órgãos e entidades que lhes permitam ampliar sua capacidade de influir no processo político e econômico internacional. Exemplos disso têm sido o interesse reafirmado em diversas ocasiões de fazer parte de organismos como a OCDE (Organização para a Cooperação e o Desenvolvimento Econômico) e o Conselho de Segurança das Nações Unidas (ONU). Contudo, apesar de Brasil e México não se confundirem com a grande maioria dos países de baixíssima relevância no panorama internacional, ainda não alcançaram o status de potências internacionais independentes. Esse é o motivo pelo qual tais países devem adotar estratégias internacionais conjuntas visando a maximizar sua capacidade de influência econômica e política no plano internacional. Como bem apontado por Keohane, as potências médias têm conseguido "exercer um papel significativo no sistema internacional atuando através de grupos ou alianças. ${ }^{20}$ "

Nesse sentido, México e Brasil e também México e Mercosul vêm se aproximando $^{21}$ Já em 1995, o então secretário de Relações Exteriores do México, José Angel Gurría Treviño, em visita a Buenos Aires, afirmou: "Traigo um mensage de integración y cooperación con el Mercosur. Ya no se trata de uno más uno, sino de quatro más uno ${ }^{22}$ " Em julho de 2002, México e Brasil assinaram um acordo de complementação econômica. ${ }^{23}$ No mesmo mês, também foi assinado um acordo de

20. R. KEOHANE, Small States in the International Politics, cit., p. 292.

21. De acordo com especialistas, o que emperrava o avanço das relações entre México e Brasil era uma disputa pela liderança da América Latina, já que os dois países são as duas maiores economias da região. Atualmente, diplomatas de ambos os países acreditam que essa rixa já esteja plenamente superada.

22. Essa visita ocorreu em 24 de maio de 1995 e referência a ela é feita em V. G. ARNAUD, Las Relaciones Exteriores del Mercosur, discurso proferido no XX Congresso Internacional de la Latin American Studies Association, Continental Plaza Hotel, Guadalajara, México, disponível in htpp:Il. 158. 105/ LASA97/arnaud.pdf.

23. Acordo de Complementação Econômica n. 53 entre os Governos da República Federativa do Brasil e dos Estados Unidos Mexicanos, de 3 de julho de 2002, assinado em Brasília. O objetivo do acordo é estabelecer normas e disciplinas para as relações econômicas e comerciais entre Brasil e México, impulsionar o desenvolvimento e diversificação do comércio para intensificar a complementação econômica, estimular os fluxos de investimentos e incentivar a participação dos setores privados. Por 
complementação econômica Mercosul-México. ${ }^{24}$ Entre os motivos que determinaram a assinatura de tais acordos, foi ressaltada a importância que a integração regional representa para os países da América Latina para alcançar um maior desenvolvimento econômico e social. Na seqüência desses acordos, ${ }^{25}$ foi assinado um acordo de complementação econômica entre México e Mercosul no setor automotivo. ${ }^{26}$ O México, mediante esse acordo bem restrito de cotas, está tendendo a tornar-se um dos principais mercados para a indústria automobilística brasileira. Em 2002, o Brasil foi o maior parceiro comercial do México na América Latina e Caribe, representando 22,6\% de todo o comércio realizado com a região. Por exemplo, somente no primeiro semestre de 2002, o comércio bilateral movimentou mais de US $\$ 1,2$ bilhão, valor cerca de $25 \%$ superior se comparado com o mesmo período do ano anterior ${ }^{27}$

Em relação à ALCA, já foi feita referência acima à posição do Brasil e do Mercosul. Quanto ao México, este, tradicionalmente, sempre teve uma postura conservadora frente à ALCA, uma vez que desde 1993 é membro do Nafta, acordo de livre comércio entre os Estados Unidos, Canadá e México ${ }^{28}$ Dependendo dos termos

meio do Decreto n. 4.383, de 23 de setembro de 2002, o Presidente da República Federativa do Brasil determinou o cumprimento de tal acordo. Segundo R. S. SANTOS, A importância de Brasil e México no contexto da integração latino-americana in Revista do Autor, ano II, n. 13, julho de 2002, p. 6, esse acordo mostra que não há mais disputa acirrada entre Brasil e México pela liderança da região.

24. Acordo de Complementação Econômica Mercosul-México n. 54 entre os governos da República Argentina, República Federativa do Brasil, República do Paraguai e República Oriental do Uruguai e os Estados Unidos Mexicanos, de 5 de julho de 2002. Esse acordo estabelece um quadro jurídico que oferece segurança e transparência aos agentes econômicos, promove os investimentos recíprocos, a complementação e cooperação econômica, bem como o desenvolvimento e a diversificação do comércio entre os países membros.

25. Deve-se aqui ressaltar o importante papel que o então ministro do Desenvolvimento, Indústria e Comércio Exterior, embaixador Sergio Amaral, teve para a concretização desses acordos.

26. Acordo de Complementação Econômica Mercosul-México n. 55 entre os governos da República Argentina, República Federativa do Brasil, República do Paraguai e República Oriental do Uruguai e os Estados Unidos Mexicanos, de 27 de setembro de 2002. Esse acordo fixa as bases para o estabelecimento do livre comércio no setor automotivo entre os países membros de forma gradual (a data limite para a total inexistência de barreiras tarifárias é 30 de junho de 2011).

27. I. MURRAY, Com visita de Lula, México aproxima-se mais do Brasil, Valor Econômico, 23 de dezembro de 2002, $I^{\circ}$ Caderno.

28. O objetivo do Nafta restringe-se à redução de tarifas entre os países meınbros. Não há proposta de integração econômica e política. O Nafta abrange uma população de 410 milhões de pessoas, sendo que o PIB total corresponde a US $\$ 9,2$ trilhōes. Entre 1990 e 2000, as exportaçōes mexicanas saltaram de US\$ 45 bilhōes para US\$ 165 bilhões anuais, ao índice de $15 \%$ ao ano. As exportações do México quadruplicaram durante a última década, constituindo cerca de uın terço do PIB. Os produtos industrializados perfazem hoje quase $90 \%$ das exportações do país, o dobro da década anterior. O México é responsável por quase metade do comércio exterior da América Latina (dados extraídos do texto P. HAKIM, Brasil e México: 
em que a ALCA for criada, o México poderá ver reduzidas suas vantagens comparativas de acesso ao mercado norte-americano, seu principal parceiro comercial, pela entrada, em condições semelhantes, de outras economias latino-americanas. Após ter arcado com os custos de uma integração assimétrica com os Estados Unidos, o México passou a dispor de certas vantagens comparativas internacionais e deve proteger seus interesses nesse sentido quando da negociação da criação da ALCA. Porém, como membro menor do Nafta, sua capacidade de influenciar por conta própria o processo de formação de ALCA é muito limitado. Uma das principais preocupações do país é com o setor agrícola $^{29} \mathrm{e}$, muito possivelmente, sozinho terá poucas chances de fazer prevalecer seus interesses sobre os americanos.

Nesse sentido, o aprofundamento da integração México-Mercosul, tendo por base uma aproximação México-Brasil, faz-se necessário, como forma de reforçar a capacidade negociadora, coletiva e de cada um dos países separadamente, assegurar maior consistência ao processo e minimizar a assimetria na distribuição dos custos e benefícios da integração americana. Para ter voz nas negociações para a criação da ALCA para frear o unilateralismo norte-americano, respaldado por sua bem estabelecida economia, não resta alternativa senão unir forças.

Essa aproximação poderá ser facilitada com a reestruturação da área diplomática brasileira responsável pelos assuntos do Mercosul e pela discussão da ALCA. O chefe da delegação brasileira nas negociações da ALCA é o embaixadior Carlos Alberto Simas Magalhães. Simas é subordinado ao embaixador Luiz Filipe de

duas maneiras de ser global in Política Externa, cit., p. 96). Essa mudança decorre em grande parte da inserção do México no Nafta. Em 1993, as transações comerciais entre os Estados Unidos e o México totalizavam US\$ 8 I bilhōes. Em 2000 , essa cifra atingiı US\$ 247 bilhões. Essa integração econôınica ınais estreita também ajudou a miniınizar os danos de longo prazo decorrentes da crise do peso mexicano no periodo 1994-95. C.A.HILLS, Livre Comércio para as Américas in Política Exrerna, v. 10, n. 2, São Paulo: Paz e Terra, p. 24, aponta que em vez de levar sete anos para o México retornar aos inercados financeiros internacionais, tal como ocorreu após a crise de 1982, o país precisou apenas de sete meses. Deve-se observar ainda que, apesar da crise, o país cresceu $8,3 \%$ no período entre 1993 e 1999 . O grau de efetividade operacional alcançado pelo Nafta e a crescente dependência da economia do México em relação aos Estados Unidos torna essa integração algo dificilmente reversível, sobretudo porque o aprofundamento dos vínculos econômicos se faz acompanhar de uma crescente convergência também no campo político (ver R.A. Barbosa, A nova geografia econômica do continente in Política Externa, v. 10, n. 2, São Paulo: Paz e Terra, p. 41).

29. Saul Muñoz López, magistrado do Tribunal Unitário Agrário de Sonora, com respaldo de diversos grupos mexicanos, aponta a necessidade de mudar a proposta americana para o setor agrícola, sob pena de fortes prejuízos ao país, uma vez que a proposta não leva em conta as diferenças de desenvolvimento entre as diversas regiōes mexicanas (disponivel em www.jornada.unam.mx/2003/feb03/030227/oriente/ puebla/puebla.htm). 
Macedo Soares, Sub-Secretário-Geral de Assuntos da América do Sul (SGAS). ${ }^{30}$ Como Soares foi representante do Brasil no México, a integração torna-se mais próxima, pela rede de contatos já existente.

\section{Atual Fase de Negociações}

As negociações da ALCA entraram numa fase decisiva: a apresentação de ofertas e prazos para desagravação tarifária. A oferta dos EUA foi tratar os países que negociam a ALCA de forma diferenciada. O Mercosul, de acordo com o critério de desenvolvimento utilizado pelos Estados Unidos foi o mais prejudicado: é a região do continente americano que terá acesso mais demorado ao mercado americano sem a cobrança de tarifas de importação sobre seus produtos. ${ }^{31}$ Muitos analistas ${ }^{32}$ entenderam essa proposta norte-americana como extremamente impositiva e discriminatória, na medida em que dita regras para $\mathrm{o}$ avanço das negociações e diferencia as preferências concedidas aos bens industriais e agrícolas dos países mais competitivos em relação aos países menos competitivos. O que mais preocupa o Brasil é a total ausência de referências na proposta americana às questões de itens sistêmicos, como subsídios e barreiras de proteção comercial (anti-dumping) que, na prática, são os maiores entraves às exportações nos setores em que o Brasil é mais competitivo.

Em sua proposta de liberalização comercial, os Estados Unidos listaram uma série de setores que devem ter suas tarifas zeradas imediatamente após a ratificação do acordo por seus futuros países membios. Entre esses setores estão o químico, o de equipamentos de construção civil e mineração, o de equipamentos elétricos, o de produtos da área de energia, o de produtos ambientais, o de tecnologia da informação, o de equipamentos médicos, o de papel, o do aço e o de produtos derivados da madeira.

30. V. D. RITTNER, Itamaraty tem novo negociador para ALCA, Gazeta Mercantil,16, 17 e 18 de maio de 2003, p. A-5. A Subsecretaria-Geral de Assuntos da América do Sul (SGAS) tem como função tratar dos assuntos políticos e econômicos da América do Sul, incluindo o Mercosul e as negociaçōes externas em que seus quatro países membros atuam como bloco, e.g., a ALCA.

31. Segundo a proposta norte-americana, os produtos industriais da região do Caribe serão favorecidos com a eliminação imediata de $91 \%$ do universo tarifário para os Estados Unidos, os da América Central, de $66 \%$, os da Comunidade Andina das Nações (CAN) de $61 \%$ e os do Mercosul, de 58\%. A diferenciação na área agrícola mostra-se ainda mais desfavorável para os países do Mercosul: os Estados Unidos propōeın a eliminação de $85 \%$ das tarifas dos produtos importados do Caribe, de $64 \%$ dos da América Central, de $68 \%$ dos da CAN e de $50 \%$ dos do Mercosul.

32. V. S. HABERFELD, O que o Brasil espera da ALCA in Gazeta Mercantil, 19 de maio de 2003 , p. A-3. 
A questão dessa oferta está em que ela exige reciprocidade para que as tarifas sejam eliminadas, mas a maioria dos produtos para os quais os Estados Unidos querem liberalização não tem competitividade similar nos países do Mercosul.

Outro ponto da proposta americana é a eliminação das tarifas do setor têxtil até o final de 2010. Entretanto, o Acordo Multifibras da OMC prevê a eliminação total dessas barreiras até o final de 2004. Na verdade, o que parece embasar essa proposta é a intenção dos Estados Unidos de ganhar tempo para promover a competitividade de sua indústria nesse setor.

Vê-se que apenas um bloco suficientemente forte pode fazer frente à unilaterização do processo de formação da ALCA por parte dos Estados Unidos. Somente assim será seguido um dos princípios que deveria ser norteador da criação da ALCA: a cláusula da nação mais favorecida. Esta prevê que quando uma concessão é feita por qualquer um dos países pertencentes ao bloco, deve ser estendida aos demais, sem restrições.

As negociações entram em sua fase final, de produto a produto. Com a co-presidência da ALCA, o Brasil tem a oportunidade de barrar a tentativa norteamericana de conduzir o processo de forma unilateral. Porém, para obter sucesso nessa empreitada, faz-se necessário uma integração México-Mercosul - não num modelo " $5+1$ ", devido à peculiaridade das relações que o México tem com os Estados Unidos, mas numa relação que poderia ser expressa da seguinte forma: "(4+1)+1".

\section{Conclusão}

O tema da integração americana tomou proporções significativas com a nova configuração construída pelo sistema internacional. Trata-se de uma nova estrutura geoeconômica em curso de estruturação no continente americano que nem o Mercosul nem o México podem ficar indiferentes.

Acordos comerciais, numa economia globalizada e de interdependência complexa, devem ser vistos como instrumentos de duas mãos, que podem reservar-nos agradáveis surpresas. Nesse sentido, a ALCA é possível e pode ser muito proveitosa para os países membros do Mercosul e o México. Cada país deve preparar-se para tanto, sendo papel de cada governo proporcionar o ambiente externo e interno compatível com esse ajuste.

Nesse cenário, a integração México-Mercosul mostra-se de suma importância como forma de fazer prevalecer os interesses do México, Argentina, Brasil, 
Paraguai e Uruguai na mesa de negociações para a criação da ALCA, principalmente nesta fase final do cronograma das negociações. O peso de duas potências regionais México e Brasil, membro do Mercosul - mostra-se como uma importante forma de contrapor-se ao domínio das negociações pelos Estados Unidos, contribuindo para fomentar o equilíbrio das relações no continente americano.

São Paulo, maio de 2003. 
Bibliografia

ALBUQUERQUE, José Augusto Guilhon. AALCA na política externa brasileira in Política Externa, v. 10, n. 2, São Paulo: Paz e Terra, pp. 7-20.

ARNAUD, Vicente Guillermo. Las Relaciones Exteriores del Mercosur, discurso proferido no XX Congresso Internacional de la Latin American Studies Association, Continental Plaza Hotel, Guadalajara, México, disponível in htpp:II.158.105/LASA97/arnaud.pdf.

BANDEIRA, Moniz, Relą̧ões Brasil-Estados Unidos no contexto da globalização, $2^{a}$ ed. revista e ampliada, São Paulo: Senac, 1998.

BARBOSA, Rubens Antonio. O Impacto da ALCA sobre o Mercosul, Revista Brasileira de Comércio Exterior RBCE, Rio de Janeiro: Fundação Centro de Estudos do Comércio Exterior, p. 6.

CARMO, Maria. Mercosul decide negociar em conjunto entrada na ALCA in Valor Econômico, 5 de fevereiro de 2003, $1^{\circ}$ Caderno.

COSTA, Roberto Teixeira da. ALCA 2005: destino ou opção, in Política Externa, v. 10, n. 2, São Paulo: Paz e Terra, pp. 102-111.

ESCOLA DE ADMINISTRAÇÃO DE LAUSANNE (IMD). Anuário de Competitividade Mundial 2003.

HABERFELD, Sérgio. O que o Brasil espera da ALCA in Gazeta Mercantil, 19 de maio de 2003, p. A-3.

HAKIM, Peter, Brasil e México: duas maneiras de ser global in Política Externa, v. 10, n. 4, São Paulo: Paz e Terra, 2001, pp. 90-105.

HILLS, Carla A. Livre Comércio para as Américas in Política Externa, v. 10, n. 2, São Paulo: Paz e Terra, pp. 21-27.

KEOHANE, Robert, Small States in the International Politics, v. 23, n. 2, 1969.

MURRAY, Isabel. Com visita de Lula, México se aproxima mais do Brasil, Valor Econômico, 23 de dezembro de 2002, $1^{\circ}$ Caderno.

NOGUEIRA, Rui. Lula quer ajuda do "companheiro" Bush para mudar o modelo, Primeira Leitura, n. 10, dezembro de 2002, pp. 24-32.

RITTNER, Daniel. Itamaraty tem novo negociador para ALCA, Gazeta Mercantil de 16, 17 e 18 de maio de 2003, p. A-5

SANTOS, Rui da Silva. A importância de Brasil e México no contexto da integração latino-americana in Revista do Autor, ano II, n. 13, julho de 2002, 8 p.

SENNES, Ricardo Ubiraci. A ALCA e as Potências Médias: Brasil e México. Série ALCA. São Paulo: FTD, 1998, v. 3.

THORSTENSEN, Vera. O Brasil diante de um tríplice desafio: negociações simultâneas da OMC, da ALCA e do acordo CE/Mercosul in Política Externa, v. 10, n. 3, São Paulo: Paz e Terra, pp. 90-112.

TRINDADE, Rui. Planalto e Itamaraty aprovam Kircher e Lavagna no poder in Gazeta Mercantil de 16, 17 e 18 de maio de 2003, p. A-4. 